\title{
Structure, Defects and Microwave Dielectric Properties of Al-doped and Al/Nd Co-doped Ba4Nd9.33Ti18054 Ceramics
}

Weijia Guo ( $\sim$ guoweijia0315@163.com )

Tsinghua University https://orcid.org/0000-0003-2481-3527

\section{Zhiyu Ma}

Tsinghua University

Yu Luo

Tsinghua University

Yugu Chen

Tsinghua University

Zhenxing Yue

Tsinghua University

\section{Longtu Li}

Tsinghua University

\section{Research Article}

Keywords: microwave dielectric ceramics, Ba4Nd9.33Ti18054, Al and Al/Nd doping, defects

Posted Date: August 11th, 2021

DOl: https://doi.org/10.21203/rs.3.rs-783511/v1

License: (1) This work is licensed under a Creative Commons Attribution 4.0 International License. Read Full License 


\section{Abstract}

$\mathrm{Ba}_{4} \mathrm{Nd}_{9.33} \mathrm{Ti}_{18-z} \mathrm{Al}_{4 z / 3} \mathrm{O}_{54}(\mathrm{BNT}-\mathrm{A}, 0 \leq z \leq 2)$ and $\mathrm{Ba}_{4} \mathrm{Nd}_{9.33+z / 3} \mathrm{Ti}_{18-z} \mathrm{Al}_{z} \mathrm{O}_{54}$ (BNT-AN, $0 \leq z \leq 2$ ) ceramics were prepared by solid state method, and the effects of the two doping methods on microwave dielectric properties were compared. As the doping amount $z$ increased, the relative dielectric constant $\left(\varepsilon_{r}\right)$ and the temperature coefficient of resonant frequency $\left(\tau_{f}\right)$ values of the ceramics decreased, and the quality factor ( $Q$, usually expressed by $Q \times f$, where $f$ is the resonant frequency) of the ceramics obviously increased when $z \leq 1.5$. With the same $z$ value, the $\varepsilon_{\mathrm{r}}$ and $Q \times f$ values of $\mathrm{Al} / \mathrm{Nd}$ co-doped ceramics are both higher than those of Al-doped ceramics. Rietveld refinement, Raman spectroscopy and thermally stimulated depolarization current (TSDC) technique were applied to clarify the relationship among the structure, defects and microwave dielectric properties. It is shown that the $Q \times f$ values of those ceramics were closely related to the strength of the $A$-site cation vibration and the concentration of oxygen vacancies (B). Excellent microwave dielectric properties of $\varepsilon_{\mathrm{r}}=72.2, Q \times f=16480 \mathrm{GHz}$, and $\tau_{f}=+14.3$ $\mathrm{ppm} /{ }^{\circ} \mathrm{C}$ were achieved in BNT-AN ceramics with $z=1.25$.

\section{Introduction}

Nowadays, the fifth-generation telecommunication (5G) technology has been developing rapidly, in which ceramic materials could play an important role [1]. Microwave dielectric ceramics with high $Q \times f$ value ( $Q$ $=1 / \tan \delta$, and $f$ is the resonant frequency) and excellent temperature stability are widely used to manufacture $5 \mathrm{G}$ antennas and filters [2-5]. In order to meet the requirements of device miniaturization, microwave dielectric ceramics having medium/high relative dielectric constant $\left(\varepsilon_{\mathrm{r}}\right)$ have been a focus of research [6], including $\mathrm{TiO}_{2}[7,8], \mathrm{Ba}_{6-3 x} \mathrm{Ln}_{8+2 x} \mathrm{Ti}_{18} \mathrm{O}_{54}$ (BLT, where $\mathrm{Ln}=$ rare earth element) [9, 10], CaO$\mathrm{Li}_{2} \mathrm{O}-\mathrm{Ln}_{2} \mathrm{O}_{3}-\mathrm{TiO}_{2}[11,12], \mathrm{Ca}_{1-x} \mathrm{Ln}_{2 x / 3} \mathrm{TiO}_{3}$ (CLT) [13-15], lead-based perovskite [16, 17], etc. In recent years, BLT with a tungsten-bronze structure and CLT with a perovskite structure have been extensively studied [18-23]. Meanwhile, novel ceramic systems such as $\mathrm{Bi}_{2}\left(\mathrm{Li}_{0.5} \mathrm{Ta}_{1.5}\right) \mathrm{O}_{7}[24,25]$ and $\mathrm{BiVO}_{4}[26,27]$ have also been developed. However, the above-mentioned ceramic materials either have a relatively low $Q \times f$ value or a relatively large temperature coefficient of resonant frequency $\left(\tau_{f}\right)$, which cannot yet meet the application needs of $5 \mathrm{G}$ technology. It is necessary to develop microwave dielectric ceramics with better comprehensive performance.

The crystal structure of BLT ceramics is composed by three types of large cation sites: $A 1$ rhombic sites, $A 2$ pentagonal sites, and $B$ sites (occupied by $\mathrm{Ti}^{4+}$ ) in the center of $\mathrm{TiO}_{6}$ octahedra [10]. According to Ohsato's report [10], $\mathrm{Ln}^{3+}$ and $\mathrm{Ba}^{2+}$ respectively occupy the $A 1$ and $A 2$ sites when $x=2 / 3$, and the ordering of $\mathrm{Ln}^{3+}$ and $\mathrm{Ba}^{2+}$ reduces the internal strain and leads to the largest $Q \times f$ value. To further improve the $Q \times f$ value of BLT ceramics, a large amount of doping modification research was displayed, especially the substitution of low-valence cations for $\mathrm{Ti}^{4+}$ at the $B$ sites. Chen et al. [28] and Tao et al. [29] replaced $\mathrm{Ti}^{4+}$ with the same amount of $\mathrm{Al}^{3+}$ to improve the $Q \times f$ value, while the condition of charge balance was not achieved. In order to meet the condition of charge balance, one method was using composite ions such 
as $\left(\mathrm{Cr}_{1 / 2} \mathrm{Nb}_{1 / 2}\right)^{4+},\left(\mathrm{Mg}_{1 / 3} \mathrm{Nb}_{2 / 3}\right)^{4+}$ or $\left(\mathrm{Al}_{1 / 2} \mathrm{Nb}_{1 / 2}\right)^{4+}$ to substitute $\mathrm{Ti}^{4+}$ [30-32], yet it complicated the synthesis process. The other method is using excessive trivalent cations (4/3 times in stoichiometry) such as $\mathrm{Cr}^{3+}, \mathrm{Al}^{3+}$ or $\mathrm{Ga}^{3+}$ to substitute $\mathrm{Ti}^{4+}[33-36]$, yet none of the studies have explained which site these cations entered. Considering that the $A 1$ sites of BLT structure are usually not fully filled, the excessive cations might enter the $A 1$ sites. However, the radii of those cations are much smaller than the size of the $A 1$ sites, which might affect the stability of the crystal lattice and lead to the deterioration of the $Q \times f$ value. Therefore, it is important to conduct a further study on the ion occupancy during these doping process.

The present study proposes a new method to maintain the condition of charge balance in the doping process in $\mathrm{Ba}_{4} \mathrm{Nd}_{9.33} \mathrm{Ti}_{18} \mathrm{O}_{54}$ (BNT) ceramics, with a chamical formula of $\mathrm{Ba}_{4} \mathrm{Nd}_{9.33+z / 3} \mathrm{Ti}_{18}-\mathrm{Al}_{z} \mathrm{O}_{54}(\mathrm{BNT}-$ $\mathrm{AN}, 0 \leq z \leq 2)$ : using the same amount of $\mathrm{Al}^{3+}$ to substitute $\mathrm{Ti}^{4+}$, and adding $\mathrm{Nd}^{3+}$ to fill the vacancies at the $A 1$ site simultaneously. Correspondingly, $\mathrm{Ba}_{4} \mathrm{Nd}_{9.33} \mathrm{Ti}_{18-z} \mathrm{Al}_{4 z / 3} \mathrm{O}_{54}$ (BNT-A, $\left.0 \leq z \leq 2\right)$ ceramics are also prepared for comparison. The theoretical solid solubility should reach when $z=2$, at which the vacancies at the $A 1$ site could be completely filled. Rietveld refinement, Raman spectroscopy and thermally stimulated depolarization current (TSDC) are applied to analyze the crystal structure and the strength of the $A$-site cation vibration. Microwave dielectric ceramics with better comprehensive performance are obtained through $\mathrm{Al} / \mathrm{Nd}$ co-doping, and the relationship between the structure and the microwave dielectric properties of the ceramics is discussed in the present work.

\section{Experimental Procedure}

The BNT-A and BNT-AN ceramics were prepared through the traditional solid-state processing. High-purity powders including $\mathrm{BaCO}_{3}$ (99.8\%, Alfa Aesar), $\mathrm{Nd}_{2} \mathrm{O}_{3}$ (99.9\%, Aladdin), $\mathrm{TiO}_{2}$ (99.99\%, Macklin), and $\mathrm{Al}_{2} \mathrm{O}_{3}$ (99.99\%, Aladdin) were used as the raw materials. All the raw powders were calcined at $600{ }^{\circ} \mathrm{C}$ for 4 hours, weighed according to the stoichiometric composition and ball milled for 4 hours in ethanol. After drying, the mixture was calcined at $1150^{\circ} \mathrm{C}$ for 4 hours, then re-milled and dried. The dried powders were ground with polyvinyl alcohol solution (PVA, $5 \mathrm{wt} \%$ ) and uniaxially pressed into cylinders with a diameter of $10 \mathrm{~mm}$ and an appropriate thickness. Finally the specimens were preheated at $600{ }^{\circ} \mathrm{C}$ for 4 hours to remove the binder and sintered in the range of $1350{ }^{\circ} \mathrm{C}$ and $1550{ }^{\circ} \mathrm{C}$ for 4 hours.

The surfaces of the sintered ceramics were observed by scanning electron microscopy (SEM; MERLIN VP Compact, Carl Zeiss, Germany). The phase compositions and crystal structures of the ceramics were analyzed by X-ray diffraction (XRD; D8 Advance, Bruker, Karlsruhe, Germany) with Cu Ka radiation. Rietveld refinement were executed using the FullProf program [37] with XRD data collected over a $2 \theta$ range of $10^{\circ} \sim 120^{\circ}$. The bulk densities of the ceramics were determined by the Archimedes method, and the relative densities were calculated by the measured and theoretical ones. The $\varepsilon_{\mathrm{r}}$ and $\tau_{f}$ values at microwave range were measured using the Hakki-Coleman method [38] by exciting the $\mathrm{TE}_{011}$ resonant mode [39] using a vector network analyzer (HP8720ES, Hewlett-Packard, Santa Rosa, CA, USA). The Qxf values were measured using the $\mathrm{TE}_{01 \delta}$ mode in the cavity method [40]. Raman spectra $\left(20 \sim 1200 \mathrm{~cm}^{-1}\right)$ 
of the ceramics were measured on a high-resolution Raman spectrometer (LabRAM HR800, Horiba JobinYvon, France) with the existing line at $523 \mathrm{~nm}$ of a Nd/YAG laser at room temperature.

TSDC measurements were accomplished using a pA meter (6517B, Keithley, Cleveland, $\mathrm{OH}$ ), and the temperature was controlled by a quarto temperature controller of Novocontrol Technologies (Montabaur, Germany). The ceramic pellets were polished and gold electrodes were sputtered on both sides. The specimens were initially polarized under a dc electric field $\left(E_{\mathrm{p}}\right)$ at a constant temperature $\left(T_{\mathrm{p}}\right)$ for a period of time $t_{\mathrm{p}}\left(100 \mathrm{~V} / \mathrm{mm} \leq E_{\mathrm{p}} \leq 350 \mathrm{~V} / \mathrm{mm}, T_{\mathrm{p}}=300^{\circ} \mathrm{C}, t_{\mathrm{p}}=10\right.$ minutes $)$, then rapidly cooled to $-100{ }^{\circ} \mathrm{C}$ with $E_{\mathrm{p}}$ maintained to freeze the polarized defects. After $E_{\mathrm{p}}$ removed and being short-circuited for 10 minutes, the specimens were heated to $300{ }^{\circ} \mathrm{C}$ with a constant heating rate of $5{ }^{\circ} \mathrm{C} / \mathrm{min}$, with the depolarization currents continually recorded.

\section{Results And Discussion}

Figure 1 presents the SEM photographs of the surface morphology of the ceramic samples. All BNT-A and BNT-AN samples show a single phase of rod-like grains. As shown in Fig. 1(a)-(c), BNT-A ceramics with different $z$ values could be well-sintered at $1400{ }^{\circ} \mathrm{C}$, indicating that the sintering temperature of the BNT-A ceramics is stable at around $1400{ }^{\circ} \mathrm{C}$, and basically does not change with the doping amount. In comparison, BNT-AN ceramics with $z=2$ are well-sintered at $1550{ }^{\circ} \mathrm{C}$ as shown in Fig. 1(f), illustrating that the sintering temperature of the BNT-AN ceramics increases with increasing doping amounts. Figure $1(d)$ (e) show that the grain size of the ceramics with the same composition becomes larger as the sintering temperature gets higher.

The XRD patterns of the ceramic samples are shown in Fig. 2. All samples can be confirmed as a single phase with a tungsten-bronze structure $\left(\mathrm{Ba}_{3.99} \mathrm{Sm}_{9.34} \mathrm{Ti}_{18} \mathrm{O}_{54}, \mathrm{PDF} \# 89-4356\right)$. The detailed XRD data with a $2 \theta$ range of $31^{\circ} \sim 35^{\circ}$ are presented in Fig 2(b), which shows that the peaks shift towards higher degrees as $z$ value increases, indicating that the cell volume decreases. This demonstrates that $\mathrm{Al}^{3+}$ with a smaller ionic radius $(0.54 \AA, \mathrm{CN}=6)$ successfully enters into the lattice and substitutes for $\mathrm{Ti}^{4+}$ with a larger ionic radius $(0.61 \AA, \mathrm{CN}=6)$. Rietveld refinement was performed to further explore the changes of phase composition and lattice parameters with doping amount. Figure 3(a)-(c) shows the refined results of the BNT, BNT-A $(z=1.25)$ and BNT-AN $(z=1.25)$ ceramics as examples, respectively. The fitting results are in good agreement with experimental XRD patterns. Figure 3(d) shows that there are a few peaks that cannot be fitted in the experimental data of the BNT-A ceramics, together with $\chi^{2}$ rises as $z$ value increases, indicating that a small amount of unknown secondary phase appears. In contrast, Fig. 3(e) shows that there is no secondary phase peak in the experimental data of the BNT-AN ceramics. The above-mentioned unknown secondary phase may have an impact on the microwave dielectric properties of the BNT-A ceramics.

The lattice parameters and cell volumes calculated by Rietveld refinement are shown in Fig. 4. The lattice parameters and cell volumes of the BNT-A and BNT-AN ceramics both decrease with the increase in $z$ value, and basically shows the same linear decrease trend as $z \leq 1.25$. This indicates that the type of 
trivalent cations $\left(\mathrm{Al}^{3+}\right.$ or $\mathrm{Nd}^{3+}$ ) filling the vacancies at the $A 1$ sites may have less influence on the lattice parameters in the doping process of the BNT ceramics. When $z \geq 1.25$, the lattice parameters and cell volumes of the BNT-AN ceramics continuously show a linear decreasing trend, while the decreasing trend of those of the BNT-A ceramics deviates from linearity. Combining with Fig. 3(d)(e), it can be demonstrated that such a deviation is caused by the secondary phase in the BNT-A ceramics. Therefore, the BNT-A ceramics cannot form a complete solid solution phase when more $\mathrm{Al}^{3+}$ ions are added, while the BNT-AN ceramics can form a continuous solid solution in the range of $0 \leq z \leq 2$. The detailed results of the structural parameters and reliability factors obtained by Rietveld refinement are shown in Table S1 and Table S2.

Figure 5 presents the relative densities and microwave dielectric properties of the BNT-A and BNT-AN ceramics. According to Fig. 5(a), the relative densities of almost all ceramic samples have reached higher than $97 \%$, indicating the ceramics are all well densified. When $z \geq 1$, the relative densities of the BNT-AN ceramics is lower than those of BNT-A ceramics with the same doping amount. In addition, the sintering temperature of the BNT-AN ceramics is higher with large $z$ values as illustrated in SEM results. Therefore, the BNT-AN ceramics are more difficult to be well sintered than the BNT-A ceramics. Figure 5(b)(d) show that the $\varepsilon_{\mathrm{r}}$ and $\tau_{f}$ values of the ceramics decrease in a similar trend with the increase in $z$ value, which is consistent with the reports of low-valence cations doping at the $B$ sites in BLT system [28-36]. According to Shannon's rule [41], $\varepsilon_{\mathrm{r}}$ is related to the ionic polarizability $\left(a_{\mathrm{D}}\right)$ and the molecular volume $\left(V_{\mathrm{m}}\right)$ :

$$
\alpha_{\mathrm{D}}=\frac{V_{\mathrm{m}}\left(\varepsilon_{\mathrm{rc}}-1\right)}{\mathrm{b}\left(\varepsilon_{\mathrm{rc}}+2\right)}
$$

where $\varepsilon_{\mathrm{rc}}$ is the corrected dielectric constant and $\mathrm{b}$ is a constant equal to $4 \pi / 3$. According to Eq. (1), $\varepsilon_{\mathrm{rc}}$ increases when $a_{\mathrm{D}}$ increases or $V_{\mathrm{m}}$ decreases. Although the cell volume of the ceramics decreases slightly when $z$ value increases as shown in Fig. 4 , the decrease in $a_{\mathrm{D}}\left[a\left(\mathrm{Al}^{3+}\right)<a\left(\mathrm{Ti}^{4+}\right)\right]$ may mainly dominate the decrease in $\varepsilon_{\mathrm{r}}$. Reaney et al. [6] reported that $\tau_{f}$ is usually determined by $\varepsilon_{\mathrm{r}}$, and the change trends of $\varepsilon_{\mathrm{r}}$ and $\tau_{f}$ are often similar in the same ceramic system. When $\mathrm{z} \geq 1.25$, the decrease in $\varepsilon_{\mathrm{r}}$ of the BNT-A ceramics slows down, and may be related to the small amount of secondary phase, consistent with the previous results of Al-doping in BLT system [35]. Figure 5(c) shows that when $z \leq 1.5$, the $Q \times f$ values of the ceramics significantly increase as $z$ value increases, which may be related to the decline in the activity of illustrated by TSDC technique in our past research [35]. As $z \geq 1.5$, the continuous doping makes the $Q \times f$ values of the ceramics decrease slightly. The decrease in the $Q \times f$ values of the BNT-A ceramics may be affected by the secondary phase, and that of BNT-AN ceramics may be related to the decline of densification. BNT-AN ceramics with $z=1.25$ have reached excellent microwave dielectric properties: $\varepsilon_{\mathrm{r}}=72.2, Q \times f=16480 \mathrm{GHz}$, and $\tau_{f}=+14.3 \mathrm{ppm} /{ }^{\circ} \mathrm{C}$.

It is noticed from Fig. 5(b)(c) that when $z \leq 1.5$, the $\varepsilon_{\mathrm{r}}$ and $Q \times f$ values of the BNT-AN ceramics are both higher than those of the BNT-A ceramics with the same doping amount, indicating that Al/Nd co-doping may be a superior strategy for substitution in the BNT ceramics. The comparison of the $\varepsilon_{\mathrm{r}}$ and $Q \times f$ values 
of these ceramics is visually presented in Fig. 6. This important difference in microwave dielectric properties may be related to factors such as the composition, structure and defects of the ceramics. The trivalent cations filling the vacancies at the $A 1$ sites have different polarizabilities $\left[a\left(\mathrm{Al}^{3+}\right)<a\left(\mathrm{Nd}^{3+}\right)\right]$, which results in higher $\varepsilon_{\mathrm{r}}$ values of BNT-AN ceramics according to Shannon's rule [41]. As for the $Q \times f$ values, the determinants may become more complicated: in addition to the secondary phase and porosity that have been discussed, the defects and stability of crystal lattice may also play an important role [6]. Bond length, bond strength and bond energy are important factors that reflect the stability of crystal lattice, and have been used to explore the relationship between the structure and properties of microwave dielectric properties [42-44]. However, according to the results of Rietveld refinement, the variation of the average bond length of the ceramics related to $z$ value is less than $0.01 \AA$, which is roughly equivalent to the uncertainty of Rietveld refinement method ( 0.006 $\AA$ ). The average bond length of $A 1-0$ is shown in Fig. S1 as an example. These data could hardly be used for further analysis. Therefore, Raman spectroscopy and TSDC technique are performed to further explore the relationship among the crystal structure, defects and $Q \times f$ values of the ceramics.

Raman spectroscopy can reflect the lattice vibration information of materials. The polarization mechanism of dielectrics in the microwave frequency band is mainly ion displacement polarization [45], which is closely related to the vibration of ions in the crystal lattice. Therefore, Raman spectroscopy is a powerful tool for studying the relationship between the structure and properties of microwave dielectric ceramics [20,32,46-52]. The space group of the BLT superlattice with tungsten-bronze structure is Pbnm (No. 62), and there are 24 Raman active vibration modes: $7 A_{g}+7 B_{g}+5 B_{2 g}+5 B_{3 g}$ [53]. The Raman spectra results of the BNT-A and BNT-AN ceramics are presented in Fig. 7. A total of 17 Raman vibration modes were observed in the experimental data. As the Raman spectra of the BLT system are excessively complex, previous studies had different opinions on the identification of Raman modes. Nevertheless, most studies considered that the Raman vibration modes in the region of $100 \sim 200 \mathrm{~cm}^{-1}$ correspond to $A$ site cations translation. The vibration modes in the regions of $200 \sim 400 \mathrm{~cm}^{-1}$ and $400 \sim 600 \mathrm{~cm}^{-1}$ were attributed to the rotation and the internal vibration of the $\mathrm{TiO}_{6}$ octahedra, respectively. The mode at 757 $\mathrm{cm}^{-1}$ might correspond to the second order scatter [20,32,50-52]. Limited by the test conditions, vibration modes between $50 \mathrm{~cm}^{-1}$ and $100 \mathrm{~cm}^{-1}$ in BLT system have not been reported yet. Previous studies on perovskite systems such as $\mathrm{SmAlO}_{3}, \mathrm{NdNiO}_{3}, \mathrm{LaGaO}_{3}$ and $\mathrm{BaCeO}_{3}$, which also have the space group symmetry Pbnm, reported Raman modes in the region of $50 \sim 100 \mathrm{~cm}^{-1}$ and identified all those modes as A-site cations translation [54-58]. Therefore, in the BNT-A and BNT-AN systems, the vibration modes between $50 \mathrm{~cm}^{-1}$ and $100 \mathrm{~cm}^{-1}$ are identified as $A$-site cations translation as well as the vibration modes between $100 \mathrm{~cm}^{-1}$ and $200 \mathrm{~cm}^{-1}$. It is reported that the mode at $234 \mathrm{~cm}^{-1}$ was considered as the tilting vibration of the $\mathrm{TiO}_{6}$ octahedra when the $A$ sites are occupied by $\mathrm{Ba}^{2+}[47,53]$. The doping methods in the present work have not made any changes to the $\mathrm{Ba}^{2+}$ cations occupying the $A 2$ sites, so it can be considered that this mode does not change significantly. In order to compare the intensities of the Raman modes, the relative intensities of the Raman spectra in Fig. 7 were obtained by normalizing the experimental intensities based on the peak values of the Raman mode at $234 \mathrm{~cm}^{-1}$. 
As shown in Fig. 7, with the increase in $z$ value, most of the Raman modes present a blue-shift, which indicates that the cell volume decreases $[20,32,48,51,52]$, consistent with the XRD results. The relative intensities of the vibration modes in the region of $300 \sim 400 \mathrm{~cm}^{-1}$ increase slightly as $z$ value increases, implying that the tilting vibration of the $\mathrm{TiO}_{6}$ octahedra becomes stronger, and the decline of $\tau_{f}$ is related to this phenomenon $[47,50,52]$. The more obvious changes appear in the vibration modes between $50 \mathrm{~cm}^{-}$ 1 and $200 \mathrm{~cm}^{-1}$, which are identified as $A$-site cations translation. As $z$ value increases, the relative intensities of these Raman modes are significantly reduced, where the variation of relative intensities of the Raman modes at $80 \mathrm{~cm}^{-1}$ and $94 \mathrm{~cm}^{-1}$ is shown in Fig. 8 as an example. It represents that the $A$-site cations translation is weakened, indicating that the binding force towards the $A$-site cations is strengthened, and accordingly the contribution to the microwave dielectric loss is reduced and the $Q \times f$ values increase. Comparing the Raman spectra of BNT-A and BNT-AN ceramics with the same $z$ value, it is found that the relative intensities of the Raman modes at $80 \mathrm{~cm}^{-1}$ and $94 \mathrm{~cm}^{-1}$ of the BNT-AN ceramics are lower than those of the BNT-A ceramics, as shown in Fig. 8. It is implied that the strength of the A-site cation vibration in the BNT-AN ceramics is weaker, so the contribution to the microwave dielectric loss is lower and the $Q \times f$ values is higher. Briefly, the present work has established the relationship between the $Q \times f$ values and the strength of the A-site cation vibration in the BNT-A and BNT-AN systems through Raman spectroscopy.

TSDC technique can provide valuable information on the types and concentrations of defects in dielectrics, and has been widely used to explore the dielectric response mechanism of ceramics $[35,59$ 66]. Liu et al. [59] firstly reported the method for determining the types of defects in inorganic dielectrics through the changes in peak position ( $T_{m}$, the temperature at which the absolute value of current density is maximized) and peak intensity ( $J_{m}$, the maximum of the absolute value of current density) of the TSDC curves with various polarization conditions $\left(T_{\mathrm{p}}\right.$ and $\left.E_{\mathrm{p}}\right)$, and Zhang et al. [64] applied this method to microwave dielectric ceramics for the first time. Figure 9 shows the TSDC curves of the BNT, BNT-A ( $z=$ $1.25)$ and BNT-AN $(z=1.25)$ ceramics. The curves of all samples show three or four TSDC peaks, indicating that there are at least three or four defect relaxation mechanisms, respectively. In the range of $50{ }^{\circ} \mathrm{C}<T_{\mathrm{m}}<150{ }^{\circ} \mathrm{C}$, there is a weak peak (referred to as peaks $\mathrm{A}_{1}, \mathrm{~A}_{2}$ and $\mathrm{A}_{3}$ ) in each figure. And peaks similar to each other (referred to as peaks $\mathrm{B}_{1}, \mathrm{~B}_{2}$ and $\mathrm{B}_{3}$ ) are displayed in the range of $160{ }^{\circ} \mathrm{C}<T_{\mathrm{m}}<200$ ${ }^{\circ} \mathrm{C}$. The TSDC curves of different samples are quite different in the high temperature section above 200 ${ }^{\circ} \mathrm{C}$. The curves of undoped sample exhibit a very strong peak (referred to as peak $\mathrm{D}_{1}$ ), and its $T_{\mathrm{m}}$ values have exceeded the test range. The curves of two doped samples both show peaks with similar changes (referred to as peaks $\mathrm{C}_{2}$ and $\mathrm{C}_{3}$ ) at around $240{ }^{\circ} \mathrm{C}$. The TSDC curves of the BNT-A $(z=1.25)$ ceramics also show a weak peak (referred to as peak $\mathrm{D}_{2}$ ) with $T_{\mathrm{m}}>280^{\circ} \mathrm{C}$.

The $T_{\mathrm{m}}$ and $J_{\mathrm{m}}$ of peaks $\mathrm{A}_{1}$ and $\mathrm{A}_{3}$ both increase with an increase in $E_{\mathrm{p}}$, indicating that these peaks are likely related to the relaxation of . As $E_{\mathrm{p}}$ increases, the $J_{\mathrm{m}}$ of peak $\mathrm{A}_{2}$ increases while the $T_{\mathrm{m}}$ decreases, indicating that peak $A_{2}$ may be related to the relaxation of trapped charges. Using the initial rise method $[64,67]$, the activation energies of peaks $A_{1}, A_{2}$ and $A_{3}$ are calculated as $0.43 \sim 0.50 \mathrm{eV}, 0.14 \sim 0.17 \mathrm{eV}$ and 
$0.24 \sim 0.36 \mathrm{eV}$, respectively. Based on previous results $[35,62,63]$, the activation energies of peaks $A_{1}$ and $A_{3}$ are close to those of the in-grain, and it can be inferred that these peaks are related to the relaxation of the in-grain . The $T_{m}$ and activation energy of peak $A_{2}$ are similar to those of peaks $A_{1}$ and $A_{3}$, and it is speculated that peak $A_{2}$ may correspond to trap charges associated with the in-grain. Peaks $B_{1}, B_{2}, B_{3}, C_{2}$ and $\mathrm{C}_{3}$ have $T_{\mathrm{m}}$ values which basically unchanged with polarization conditions, while their $J_{\mathrm{m}}$ values increase with an increase in $E_{\mathrm{p}}$, indicating that they may be related to the relaxation of defect dipoles. The calculated activation energies of peaks $\mathrm{B}_{1}, \mathrm{~B}_{2}$ and $\mathrm{B}_{3}$ are $0.58 \sim 0.80 \mathrm{eV}, 0.64 \sim 0.75 \mathrm{eV}$ and $0.59 \sim 0.75 \mathrm{eV}$, respectively. According to the results from previous studies $[35,61,68]$, it can be inferred that peak $B$ is related to the relaxation of the defect dipoles. Although the activation energies of peaks $C_{2}$ and $C_{3}$ are difficult to calculate by the initial rise method, the type of defects related to peak $\mathrm{C}$ could be determined by the defect reactions in the doping process, considering that peak $\mathrm{C}$ appears only after doping. During the substitution process of $\mathrm{Al}^{3+}$ for $\mathrm{Ti}^{4+}$ at the $B$ sites, point defects are formed. Meanwhile, excess trivalent cations $\left(\mathrm{Al}^{3+}\right.$ or $\mathrm{Nd}^{3+}$ ) were added to fill the vacancies at the $A 1$ sites, forming or point defects. Thus the condition of charge balance could be ensured, without ion valence changing or producing. Therefore, peak $\mathrm{C}_{2}$ and $\mathrm{C}_{3}$ are considered as the relaxation peaks of the and defect dipoles, respectively. As for peak $D_{1}$, the current density rises slower when $E_{\mathrm{p}}$ is higher, indicating that it will reach a peak value at a higher temperature with higher $E_{\mathrm{p}}$, which signifies that peak $\mathrm{D}_{1}$ may be related to the relaxation of . The calculated activation energy of peak $D_{1}$ is $0.98 \sim 1.19 \mathrm{eV}$, similar to that of the across-grain-boundary $(1.1 \mathrm{eV})[35,60]$. It is implied that peak $D_{1}$ is likely related to the relaxation of the across-grain-boundary . Since the position of peak $D_{2}$ is similar to peak $D_{1}$, it is speculated that the relaxation mechanisms of the two are the same, so that it can be considered that peak $D_{2}$ is also related to the relaxation of the acrossgrain-boundary .

TSDC peaks with higher $J_{m}$ imply a higher concentration of the corresponding defects $[66,69]$. Comparing the TSDC curves of the three ceramic samples, the BNT ceramics with peak $D_{1}$ in Fig. 9(a) show an extremely high concentration of the across-grain-boundary, while the BNT-A $(z=1.25)$ ceramics with peak $\mathrm{D}_{2}$ in Fig. 9 (b) show only a small amount of across-grain-boundary, and the BNT-AN $(z=1.25)$ ceramics show no peaks corresponding to across-grain-boundary in Fig. 9(c). It is generally believed that oxygen vacancies could cause the extrinsic loss of dielectric ceramics and affect the $Q \times f$ values at microwave frequency bands [6]. The TSDC results in the present work are consistent with it. It is noticed that each $\mathrm{O}^{2-}$ in the crystal lattice is adjacent to several $A$-site cations in BLT system. Associating the results of TSDC with the aforementioned Raman spectroscopy of the BNT-A and BNT-AN ceramics, it can be found that with the strengthening of binding force between the $A$-site cations and $\mathrm{O}^{2-}$, the formation of becomes difficult, indicating that the results of TSDC and Raman spectroscopy are consistent. It is demonstrated for the first time that in the BNT-A and BNT-AN ceramics, the formation of in the crystal lattice is closely related to the strength of the $A$-site cation vibration, and affects the lattice vibration then affects the microwave dielectric loss. 


\section{Conclusions}

The Al-doped and Al/Nd co-doped BNT ceramics are prepared through the solid state processing. The microwave dielectric properties of the BNT-A and BNT-AN ceramics are compared, and the relationship among the composition, structure, defects and microwave dielectric properties of the ceramics was explored through Rietveld refinement, Raman spectroscopy and TSDC technique. As the doping amount increases, the $\varepsilon_{\mathrm{r}}$ and $\tau_{f}$ values of the ceramics decrease, and the $Q \times f$ values first increase and then slightly decrease. The $\varepsilon_{\mathrm{r}}$ and $Q \times f$ values of BNT-AN ceramics are both higher than those of BNT-A ceramics, indicating that $\mathrm{Al} / \mathrm{Nd}$ co-doping is a novel and superior doping method that maintains the condition of charge balance. The results of Rietveld refinement show that there is a small amount of unknown secondary phase in the BNT-A ceramics, and the relative density data show that the BNT-AN ceramics are more difficult to densify, which may result in the deterioration of microwave dielectric performance when $z \geq 1$.5. Raman spectroscopy and TSDC measurement together show that the $Q \times f$ values of the BNT-A and BNT-AN ceramics are closely related to the strength of the A-site cation vibration and the concentration of . With the strengthening of binding force between the $A$-site cations and $\mathrm{O}^{2-}$, the contribution of the $A$-site cations to the microwave dielectric loss reduces and the $Q \times f$ values decrease, together with that the formation of becomes difficult. It is also proved that in microwave frequency bands, oxygen vacancies affect the dielectric loss by affecting the lattice vibration. Microwave dielectric ceramics with excellent performance in the field of medium/high $\varepsilon_{\mathrm{r}}$ were obtained: $\varepsilon_{\mathrm{r}}=72.2, Q \times f=16480$ $\mathrm{GHz}$, and $\tau_{f}=+14.3 \mathrm{ppm} /{ }^{\circ} \mathrm{C}$, which could have outstanding application prospects in the $5 \mathrm{G}$ technology.

\section{Declarations}

\section{Acknowledgements}

This work was supported by the National Key Research and Development Program of China (Grant No. 2017YFB0406301), Key-Area Research and Development Program of Guangdong Province (Grant No. 2020B010176001), and the National Natural Science Foundation of China (Grant No.51872160).

\section{Electronic Supplementary Material}

Supplementary material (add a brief description) is available in the online version of this article.

\section{References}

1. Hill MD, Cruickshank DB, MacFarlane IA (2020) Perspective on ceramic materials for $5 G$ wireless communication systems. Appl Phys Lett 118:120501

2. Jin DH, Hu CC, Liu B (2021) Improved sinterability and temperature stability in $\mathrm{Zn}^{2+} / \mathrm{Ti}^{4+}-\mathrm{Co}^{-}$ substituted $\mathrm{CaAl}_{2} \mathrm{O}_{4}$ ceramics and their $5 \mathrm{G}$ antenna applications. J Mater Sci: Mater Electron 32:18205-18211 
3. Clavet Y, Manchec A, Favennec J-F et al (2009) Design of high-permittivity ceramic UHF microstrip filter for a space application. In Proc Asia Pacific Microwave Conf. Singapore, 2160-2163

4. Medeiros JLG (2012) Microstrip fractal patch antennas using high permittivity ceramic substrate. In Proc IEEE Antennas and Propagation Society Int Symp (APSURSI). Chicago, 1-2

5. Rhbanou A, Fadl AE, Jebbor $\mathrm{N}$ et al (2021) New design of miniature $\mathrm{C}$-band substrate integrated waveguide bandpass filters using ceramic material. FME Trans 49:103-112

6. Reaney IM (2006) Microwave dielectric ceramics for resonators and filters in mobile phone networks. J Am Ceram Soc 89:2063-2072

7. Cohn SB (1968) Microwave bandpass filters containing high- $Q$ dielectric resonators. IEEE Trans Microw Theory Tech 16:218-227

8. Zhao E, Hao J, Xue X et al (2021) Rutile $\mathrm{TiO}_{2}$ microwave dielectric ceramics prepared via cold sintering assisted two step sintering. J Eur Ceram Soc 41:3459-3465

9. Ohsato $\mathrm{H}$, Ohhashi T, Nishigaki et al (1993) Formation of solid solutions of new tungsten bronze-type microwave dielectric compounds $\mathrm{Ba}_{6}-3 x R 8+2 x \mathrm{Ti}_{18} \mathrm{O}_{54}(R=\mathrm{Nd}$ and $\mathrm{Sm}, 0 \leq x \leq 1)$. Jpn J Appl Phys 32:4323-4326

10. Ohsato $\mathrm{H}$ (2001) Science of tungstenbronze-type like $\mathrm{Ba}_{6}-3 x R 8+2 x \mathrm{Ti}_{18} \mathrm{O}_{54}(R=$ rare earth) microwave dielectric solid solutions. J Eur Ceram Soc 21:2703-2711

11. Ezaki K, Baba Y, Takahashi $\mathrm{H}$ et al (1993) Microwave dielectric properties of $\mathrm{CaO}-\mathrm{Li}_{2} \mathrm{O}-\mathrm{Ln}_{2} \mathrm{O}_{3}-\mathrm{TiO}_{2}$ ceramics. Jpn J Appl Phys 32:4319-4322

12. Zhou C, Chen G, Cen Z et al (2013) Structure and microwave dielectric characteristics of lithiumexcess $\mathrm{Ca}_{0.6} \mathrm{Nd}_{0.8 / 3} \mathrm{TiO}_{3} /\left(\mathrm{Li}_{0.5} \mathrm{Nd}_{0.5}\right) \mathrm{TiO}_{3}$ ceramics. Mater Res Bull 48:4924-4929

13. Yoshida $\mathrm{M}$, Hara $\mathrm{N}$, Takada $\mathrm{T}$ et al (1997) Structure and dielectric properties of $\left(\mathrm{Ca}_{1}-{ }_{x} \mathrm{Nd}_{2 x / 3}\right) \mathrm{TiO}_{3}$. Jpn J Appl Phys 36:6818-6823

14. Kim WS, Kim ES, Yoon KH (1999) Effects of $\mathrm{Sm}^{3+}$ substitution on dielectric properties of $\mathrm{Ca}_{1-}$ ${ }_{x} \mathrm{Sm}_{2 x / 3} \mathrm{TiO}_{3}$ ceramics at microwave frequencies. J Am Ceram Soc 82:2111-2115

15. Huang C-L, Tsai J-T, Chen Y-B (2001) Dielectric properties of $(1-y) \mathrm{Ca}_{1}-x \mathrm{La}_{2 x / 3} \mathrm{TiO}_{3}-y(\mathrm{Li}, \mathrm{Nd})_{1 / 2} \mathrm{TiO}_{3}$ ceramic system at microwave frequency. Mater Res Bull 36:547-556

16. Kato J, Kagata $\mathrm{H}$, Nishimoto $\mathrm{K}(1992)$ Dielectric properties of $(\mathrm{PbCa})(\mathrm{MeNb}) \mathrm{O}_{3}$ at microwave frequencies. Jpn J Appl Phys 31:3144-3147

17. Kucheiko S, Choi J-W, Kim H-J et al (1997) Microwave characteristics of (Pb,Ca)(Fe,Nb,Sn) $\mathrm{O}_{3}$ dielectric materials. J Am Ceram Soc 80:2937-2940

18. Huang X, Liu X, Liu F et al (2017) Microstructures and microwave dielectric properties of $\left(\mathrm{Ba}_{1}\right.$ $\left.{ }_{x} \mathrm{Sr}_{x}\right)_{4}\left(\mathrm{Sm}_{0.4} \mathrm{Nd}_{0.6}\right)_{28 / 3} \mathrm{Ti}_{18} \mathrm{O}_{54}$ solid solutions. J Adv Ceram 6:50-58

19. He T, Lv C, Li W et al (2020) The dielectric constant of $\mathrm{Ba}_{6-3 x}\left(\mathrm{Sm}_{1-y} \mathrm{Nd}_{y}\right)_{8+2 x} \mathrm{Ti}_{18} \mathrm{O}_{54}(x=2 / 3)$ ceramics for microwave communication by linear regression analysis. Materials 13:5733 
20. Wang G, Fu Q, Guo P et al (2021) Crystal structure, spectra analysis and dielectric characteristics of $\mathrm{Ba}_{4} \mathrm{M}_{28 / 3} \mathrm{Ti}_{18} \mathrm{O}_{54}(\mathrm{M}=\mathrm{La}, \mathrm{Pr}, \mathrm{Nd}$, and Sm) microwave ceramics. Ceram Int 47:1750-1757

21. Chen Y, Guo W, Luo Y et al (2021) Microwave and terahertz properties of porous $\mathrm{Ba}_{4}(\mathrm{Sm}, \mathrm{Nd}, \mathrm{Bi})_{28 / 3} \mathrm{Ti}_{18} \mathrm{O}_{54}$ ceramics obtained by sacrificial template method. J Am Ceram Soc 00:110. https://doi.org/10.1111/jace.17940

22. Xiong $Z$, Zhang $X$, Tang $B$ et al (2021) Characterization of structure and properties in $\mathrm{CaO}-\mathrm{Nd}_{2} \mathrm{O}_{3}-\mathrm{TiO}_{2}$ microwave dielectric ceramic modified by $\mathrm{Al}_{2} \mathrm{O}_{3}$. Mater Charact 176:111108

23. Lin S-H, Lin Z-Q, Chen C-W (2021) Microwave dielectric characterization of $\mathrm{Ca}_{0.6}\left(\mathrm{La}_{1}-{ }_{x} \mathrm{Y}_{x}\right)_{0.2667} \mathrm{TiO}_{3}$ perovskite ceramics with high positive temperature coefficient. Ceram Int 47:16828-16832

24. Zhou D, Pang L-X, Wang D-W et al (2017) High permittivity and low loss microwave dielectrics suitable for $5 \mathrm{G}$ resonators and low temperature co-fired ceramic architecture. J Mater Chem C 5:10094-10098

25. Ullah A, Liu H, Manan A et al (2021) Microwave dielectric properties of $\mathrm{Bi}_{2}\left(\mathrm{Li}_{0.5} \mathrm{Ta}_{1.5}\right) \mathrm{O}_{7}-\mathrm{TiO}_{2}$-based ceramics for $5 \mathrm{G}$ cellular base station resonator application. Ceram Int 47:8416-8423

26. Structure-property relationships (2017) of low sintering temperature scheelite-structured $(1-x) \mathrm{BiVO}_{4^{-}}$ $x \mathrm{LaNbO}_{4}$ microwave dielectric ceramics. J Mater Chem C 5:2695-2701

27. Pang L-X, Zhou D, Liu W-G et al (2018) Crystal structure and microwave dielectric behaviors of scheelite structured $(1-x) \mathrm{BiVO}_{4}-x \mathrm{La}_{2 / 3} \mathrm{MoO}_{4}(0.0 \leq x \leq 1.0)$ ceramics with ultra-low sintering temperature. J Eur Ceram Soc 38:1535-1540

28. Chen $\mathrm{H}$, Tang B, Gao A et al (2015) Aluminum substitution for titanium in $\mathrm{Ba}_{3.75} \mathrm{Nd}_{9.5} \mathrm{Ti}_{18} \mathrm{O}_{54}$ microwave dielectric ceramics. J Mater Sci: Mater Electron 26:405-410

29. Tao J, Mu M, Wang $X$ et al (2018) Improved microwave dielectric properties of anti-reduction $\mathrm{Ba}_{4}\left(\mathrm{Ce}_{0.5} \mathrm{Sm}_{0.5}\right)_{9.3} \mathrm{Ti}_{18-z} \mathrm{Al}_{z} \mathrm{O}_{54}$ ceramics sintered in nitrogen atmosphere. J Mater Sci: Mater Electron 29:1392-1398

30. Guo X, Tang B, Liu J et al (2015) Microwave dielectric properties and microstructure of $\mathrm{Ba}_{6}$ ${ }_{3 x} \mathrm{Nd}_{8+2 x} \mathrm{Ti}_{18-y}\left(\mathrm{Cr}_{1 / 2} \mathrm{Nb}_{1 / 2}\right)_{y} \mathrm{O}_{54}$ ceramics. J Alloy Compd 646:512-516

31. Chen $\mathrm{H}$, Tang B, Duan $\mathrm{S}$ et al (2015) Microstructure and microwave dielectric properties of $\mathrm{Ba}_{3.75} \mathrm{Nd}_{9.5} \mathrm{Ti}_{18-z}\left(\mathrm{Mg}_{1 / 3} \mathrm{Nb}_{2 / 3}\right)_{z} \mathrm{O}_{54}$ Ceramics. J electron mater 44:1081-1087

32. Xiong Z, Tang B, Fang Z et al (2017) Crystal structure, Raman spectroscopy and microwave dielectric properties of $\mathrm{Ba}_{3.75} \mathrm{Nd}_{9.5} \mathrm{Ti}_{18-z}\left(\mathrm{Al}_{1 / 2} \mathrm{Nb}_{1 / 2}\right)_{z} \mathrm{O}_{54}$ ceramics. J Alloy Compd 723:580-588

33. Chen $\mathrm{H}$, Xiong Z, Yuan $\mathrm{Y}$ et al (2016) Dependence of microwave dielectric properties on site substitution in $\mathrm{Ba}_{3.75} \mathrm{Nd}_{9.5} \mathrm{Ti}_{18} \mathrm{O}_{54}$ ceramic. J Mater Sci: Mater Electron 27:10951-10957

34. Tang $B$, Xiang Q, Fang Z et al (2018) Microwave dielectric properties of $\mathrm{Ba}_{3.75} \mathrm{Nd}_{9.5} \mathrm{Ti}_{18-z} \mathrm{Cr}_{4 z / 3} \mathrm{O}_{54}$ ceramics. J Mater Sci: Mater Electron 29:535-540

35. Guo W, Zhang J, Luo Y et al (2019) Microwave dielectric properties and thermally stimulated depolarization of Al-doped $\mathrm{Ba}_{4}(\mathrm{Sm}, \mathrm{Nd})_{9.33} \mathrm{Ti}_{18} \mathrm{O}_{54}$ ceramics. J Am Ceram Soc 102:5494-5502 
36. Wang G, Fu Q, Shi H et al (2020) Novel thermally stable, high quality factor $\mathrm{Ba}_{4}\left(\mathrm{Pr}_{0.4} \mathrm{Sm}_{0.6}\right)_{28 / 3} \mathrm{Ti}_{18-}$ ${ }_{y} \mathrm{Ga}_{4 y / 3} \mathrm{O}_{54}$ microwave dielectric ceramics. J Am Ceram Soc 103:2520-2527

37. Rodriguez-Carvajal J. FullProf suite 2000 (Version September 2020, Laboratoire Leon Brillouin)

38. Hakki BW, Coleman PD (1960) A dielectric resonator method of measuring inductive capacities in the millimeter range. IRE Trans Microwave Theory Tech 8:402-410

39. Courtney WE (1970) Analysis and evaluation of a method of measuring the complex permittivity and permeability microwave insulators. IEEE Trans Microwave Theory Tech 18:476-485

40. Krupka J, Derzakowski K, Riddle B et al (1998) A dielectric resonator for measurements of complex permittivity of low loss dielectric materials as a function of temperature. Meas Sci Technol 9:17511756

41. Shannon RD (1993) Dielectric polarizabilities of ions in oxides and fluorides. J Appl Phys 73:348366

42. Xia W-S, Li L-X, Ning P-F et al (2012) Relationship between bond iconicity, lattice energy, and microwave dielectric properties of $\mathrm{Zn}\left(\mathrm{Ta}_{1}-{ }_{x} \mathrm{Nb}_{x}\right)_{2} \mathrm{O}_{6}$ ceramics. J Am Ceram Soc 95:2587-2592

43. Zheng J, Yang Y, Wu H et al (2020) Structure, infrared spectra and microwave dielectric properties of the novel $\mathrm{Eu}_{2} \mathrm{TiO}_{5}$ ceramics. J Am Ceram Soc 103:4333-4341

44. Liu L, Du J, Tao B et al (2021) Structure, microwave dielectric properties, and infrared reflectivity spectrum of $\mathrm{W}^{6+}$ substituted $\mathrm{Ce}_{2} \mathrm{Zr}_{3}\left(\mathrm{MoO}_{4}\right)_{9}$ ceramics. Ceram Int 47:19142-19152

45. Sebastian MT (2008) Dielectric materials for wireless communication. Elsevier, Amsterdam

46. Chen MY, Chia CT, Lin IN et al (2006) Microwave properties of $\mathrm{Ba}\left(\mathrm{Mg}_{1 / 3} \mathrm{Ta}_{2 / 3}\right) \mathrm{O}_{3}, \mathrm{Ba}\left(\mathrm{Mg}_{1 / 3} \mathrm{Nb}_{2 / 3}\right) \mathrm{O}_{3}$ and $\mathrm{Ba}\left(\mathrm{Co}_{1 / 3} \mathrm{Nb}_{2 / 3}\right) \mathrm{O}_{3}$ ceramics revealed by Raman scattering. J Eur Ceram Soc 26:1965-1968

47. Wu SY, Li Y, Chen XM (2004) Raman spectra of Nd/Sn cosubstituted $\mathrm{Ba}_{6}-3 x \mathrm{Sm}_{8+2 x} \mathrm{Ti}_{18} \mathrm{O}_{54}$ microwave dielectric ceramics. J Appl Phys 96:5683-5686

48. Liao Q, Li L (2012) Structural dependence of microwave dielectric properties of ixiolite structured $\mathrm{ZnTiNb}_{2} \mathrm{O}_{8}$ materials: crystal structure refinement and Raman spectra study. Dalton Trans 41:69636969

49. Ning F, Gan L, Yuan S et al (2017) Correlation between vibrational modes of $A$-site ions and microwave dielectric properties in $(1-x) \mathrm{CaTiO}_{3}-x\left(\mathrm{Li}_{0.5} \mathrm{Sm}_{0.5}\right) \mathrm{TiO}_{3}$ ceramics. J Alloy Compd 729:742748

50. Wang G, Fu Q, Shi $\mathrm{H}$ et al (2019) Suppression of oxygen vacancies generation in $\mathrm{Ba}_{6}$ ${ }_{3 x} \mathrm{Sm}_{8+2 x} \mathrm{Ti}_{18} \mathrm{O}_{54}(x=2 / 3)$ microwave dielectric ceramics through Pr substitution. Ceram Int 45:22148-22155

51. Wang G, Fu Q, Guo P et al (2020) $A / B$-site cosubstituted $\mathrm{Ba}_{4} \mathrm{Pr}_{28 / 3} \mathrm{Ti}_{18} \mathrm{O}_{54}$ microwave dielectric ceramics with temperature stable and high $Q$ in a wide range. Ceram Int 46:11474-11483

52. Xiong Z, Tang B, Yang $C$ et al (2018) Correlation between structures and microwave dielectric properties of $\mathrm{Ba}_{3.75} \mathrm{Nd}_{9.5-\chi} \mathrm{Sm}_{\chi} \mathrm{Ti}_{17.5}\left(\mathrm{Cr}_{1 / 2} \mathrm{Nb}_{1 / 2}\right)_{0.5} \mathrm{O}_{54}$ ceramics. J Alloy Compd 740:492-499 
53. Wu SY, Li Y, Chen XM (2003) Raman spectra of $\mathrm{Ba}_{6}-3 x \mathrm{Sm}_{8+2 x} \mathrm{Ti}_{18} \mathrm{O}_{54}$ solid solution. J Phys Chem Solids 64:2365-2368

54. Scott JF (1970) High-temperature Raman study of samarium aluminate. Phys Rev B 1:4182-4185

55. Zaghrioui M, Bulou A, Laffez P et al (2000) Raman study of metal-insulator transition in $\mathrm{NdNiO}_{3}$ thin films. J Magn Magn Mater 211:238-242

56. Sanjuán ML, Orera VM, Merino Rl et al (1998) Raman and x-ray study of $\mathrm{La}_{1-x} \mathrm{Nd}_{x} \mathrm{GaO}_{3}(0 \leq x \leq 1)$ perovskite solid solutions. J Phys: Condens Matter 10:11687-11702

57. Tompsett GA, Sammes NM, Phillips RJ (1999) Raman spectroscopy of the $\mathrm{LaGaO}_{3}$ phase transition. J Raman Spectrosc 30:497-500

58. Loridant S, Abello L, Lucazeau G (1997) Polarized Raman spectra of single crystals of $\mathrm{BaCeO}_{3} . \mathrm{J}$ Raman Spectrosc 28:283-288

59. Liu W, Randall CA (2008) Thermally stimulated relaxation in Fe-doped $\mathrm{SrTiO}_{3}$ systems: I. single crystals. J Am Ceram Soc 91:3245-3250

60. Yoon S-H, Randall CA, Hur K-H (2010) Correlation between resistance degradation and thermally stimulated depolarization current in acceptor $(\mathrm{Mg})$-doped $\mathrm{BaTiO}_{3}$ submicrometer fine-grain ceramics. J Am Ceram Soc 93:1950-1956

61. Lee H, Kim JR, Lanagan MJ et al (2013) High-energy density dielectrics and capacitors for elevated temperatures: $\mathrm{Ca}(\mathrm{Zr}, \mathrm{Ti}) \mathrm{O}_{3}$. J Am Ceram Soc 96:1209-1213

62. Zhang $X$, Zhang $Y$, Zhang J et al (2014) Microwave dielectric properties and thermally stimulated depolarization currents study of $(1-x) \mathrm{Ba}_{0.6} \mathrm{Sr}_{0.4} \mathrm{La}_{4} \mathrm{Ti}_{4} \mathrm{O}_{15^{-}-x \mathrm{TiO}}$ ceramics. J Am Ceram Soc 97:31703176

63. Zhang X, Zhang J, Xie Z et al (2015) Structure, microwave dielectric properties and thermally stimulated depolarization currents of $(1-x) \mathrm{Ba}_{0.6} \mathrm{Sr}_{0.4} \mathrm{La}_{4} \mathrm{Ti}_{4} \mathrm{O}_{15}-\chi \mathrm{Ba}_{5} \mathrm{Nb}_{4} \mathrm{O}_{15}$ solid solutions. J Am Ceram Soc 98:1245-1252

64. Zhang J, Zhou Y, Peng B et al (2014) Microwave dielectric properties and thermally stimulated depolarization currents of $\mathrm{MgF}_{2}$-doped diopside ceramics. J Am Ceram Soc 97:3537-3543

65. Zhang J, Yue Z, Luo Y et al (2017) Understanding the thermally stimulated relaxation and defect behavior of Ti-containing microwave dielectrics: a case study of $\mathrm{BaTi}_{4} \mathrm{O}_{9}$. Mater Des 130:479-487

66. Luo Y, Zhang J, Yue Z et al (2018) Improvement in microwave dielectric properties of $\mathrm{Sr}_{2} \mathrm{TiO}_{4}$ ceramics through post-annealing treatment. J Electroceram 41:67-72

67. Hino T (1980) Thermally stimulated characteristics in solid dielectrics. IEEE Trans Electr Insul 15:301-311

68. Lee S-J, Kang K-Y, Han S-K (1999) Low-frequency dielectric relaxation of $\mathrm{BaTiO}_{3}$ thin-film capacitors. Appl Phys Lett 75:1784-1786

\section{Figures}



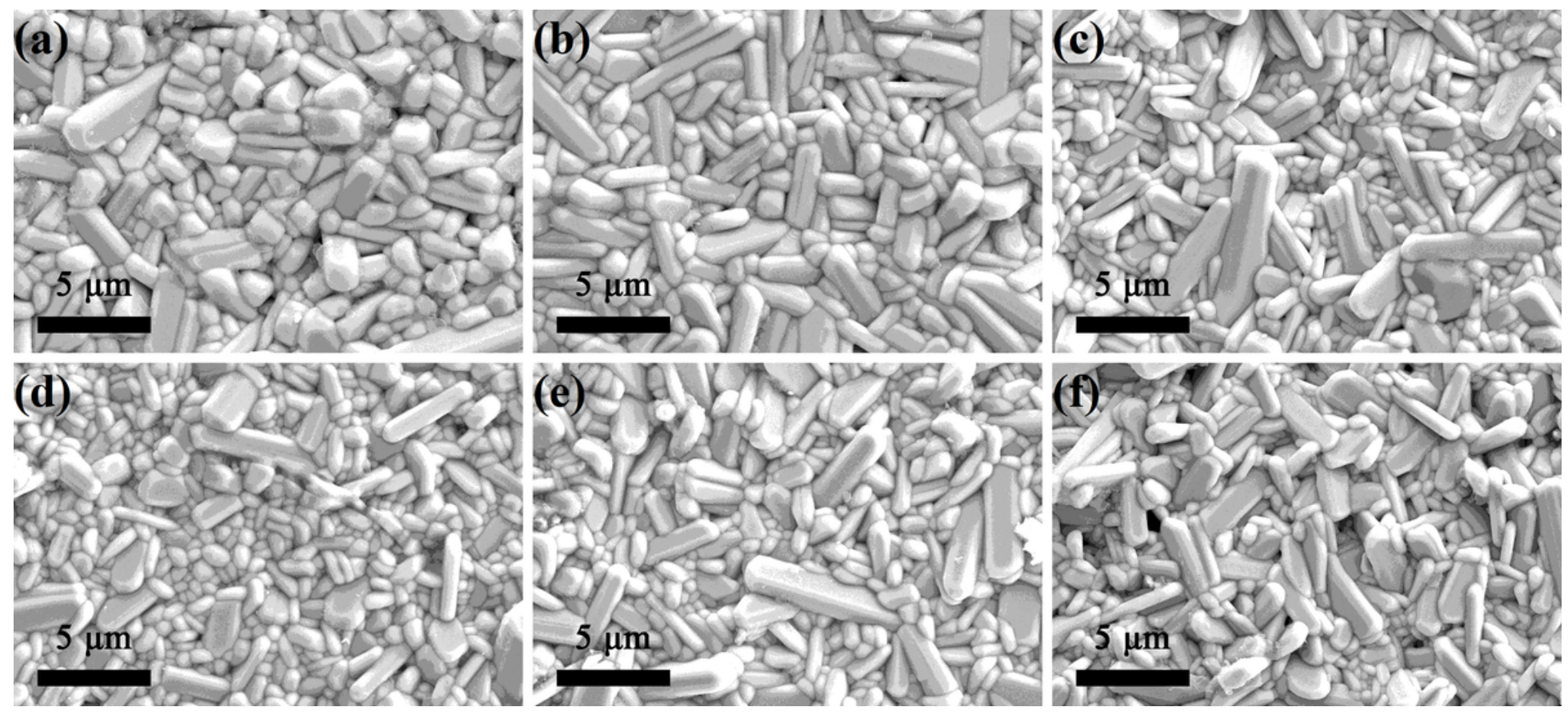

\section{Figure 1}

SEM photographs of the BNT, BNT-A and BNT-AN ceramics: (a) BNT, sintered at $1400{ }^{\circ} \mathrm{C}$; (b) BNT-A, $\mathrm{z}=$ 1.25 , sintered at $1400{ }^{\circ} \mathrm{C}$; (c) BNT-A, $z=2$, sintered at $1400{ }^{\circ} \mathrm{C}$; (d) BNT-AN, $z=1.25$, sintered at $1400{ }^{\circ} \mathrm{C}$; (e) BNT-AN, $z=1.25$, sintered at $1500{ }^{\circ} \mathrm{C}$; (f) BNT-A, $z=2$, sintered at $1550{ }^{\circ} \mathrm{C}$; 

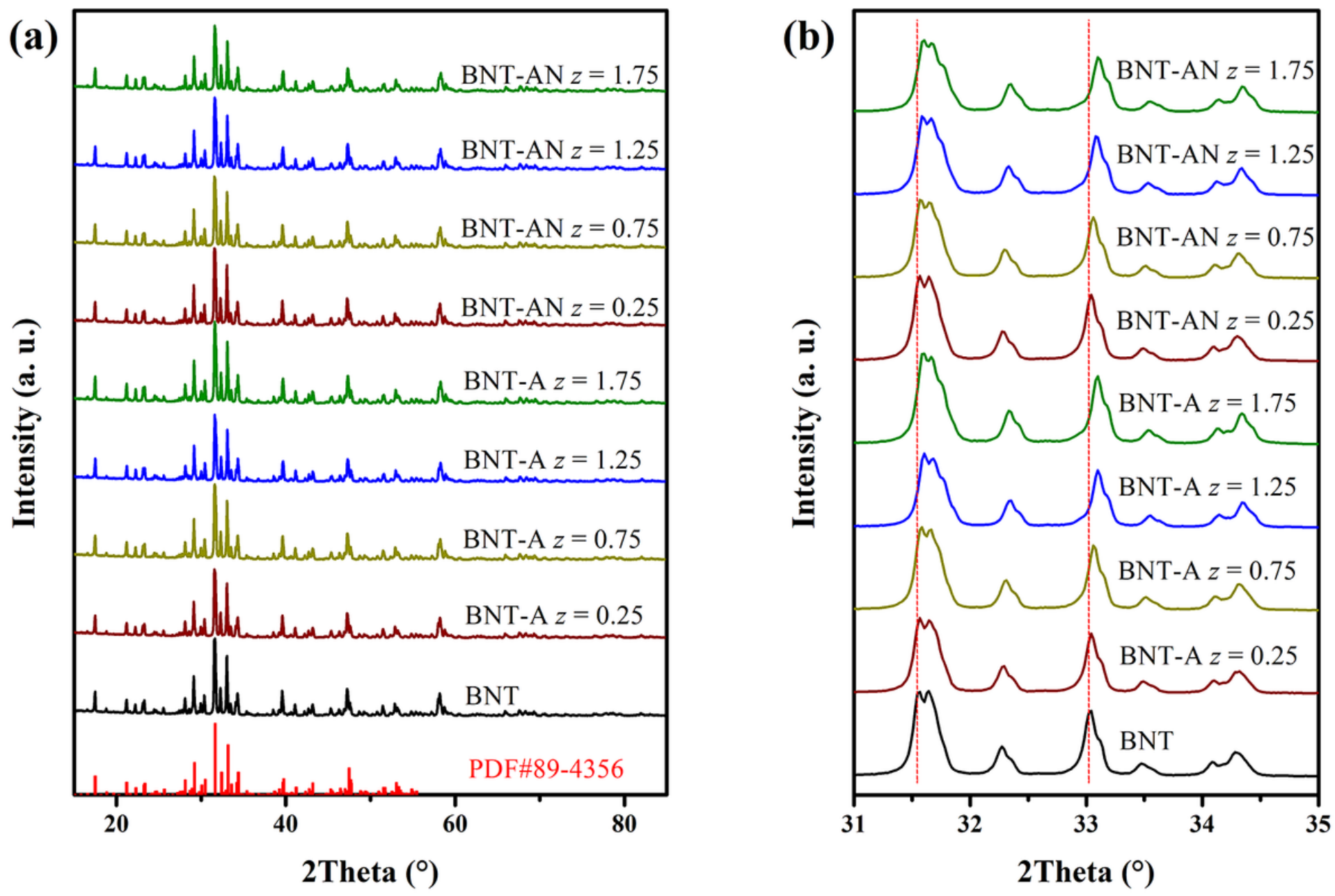

Figure 2

(a) XRD patterns of the BNT, BNT-A and BNT-AN ceramics ( $z=0,0.25,0.75,1.25,1.75)$; (b) XRD peaks shift in the range of $31^{\circ} \leq 2 \theta \leq 35^{\circ}$. 

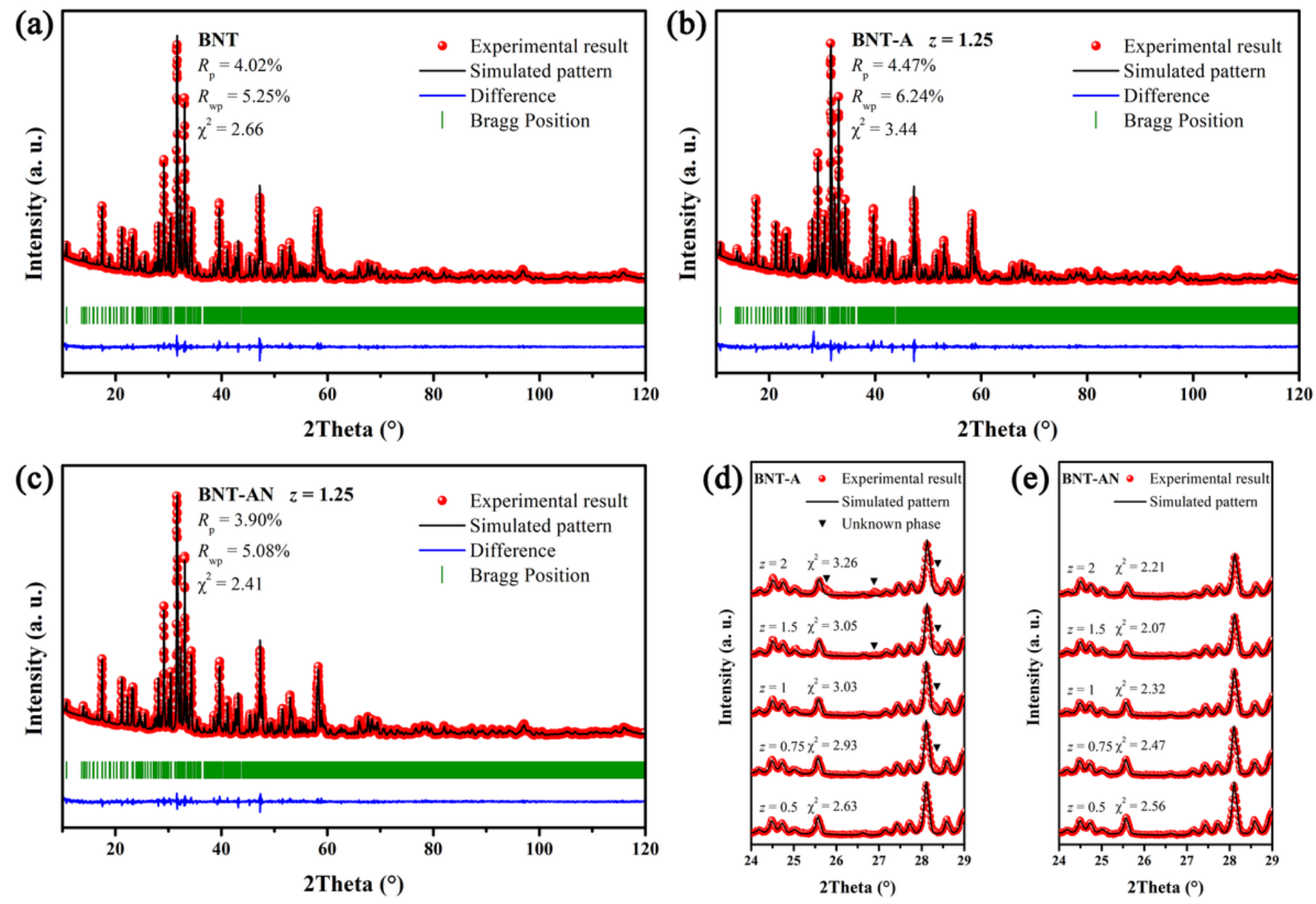

Figure 3

The Rietveld refinement results of (a) the BNT ceramics, (b) the BNT-A $(z=1.25)$ ceramics, and (c) the BNT-AN ( $z=1.25)$ ceramics; the detailed Rietveld refinements of $(d)$ the BNT-A $(0.5 \leq z \leq 2)$ ceramics and (e) the BNT-AN $(0.5 \leq z \leq 2)$ ceramics. 


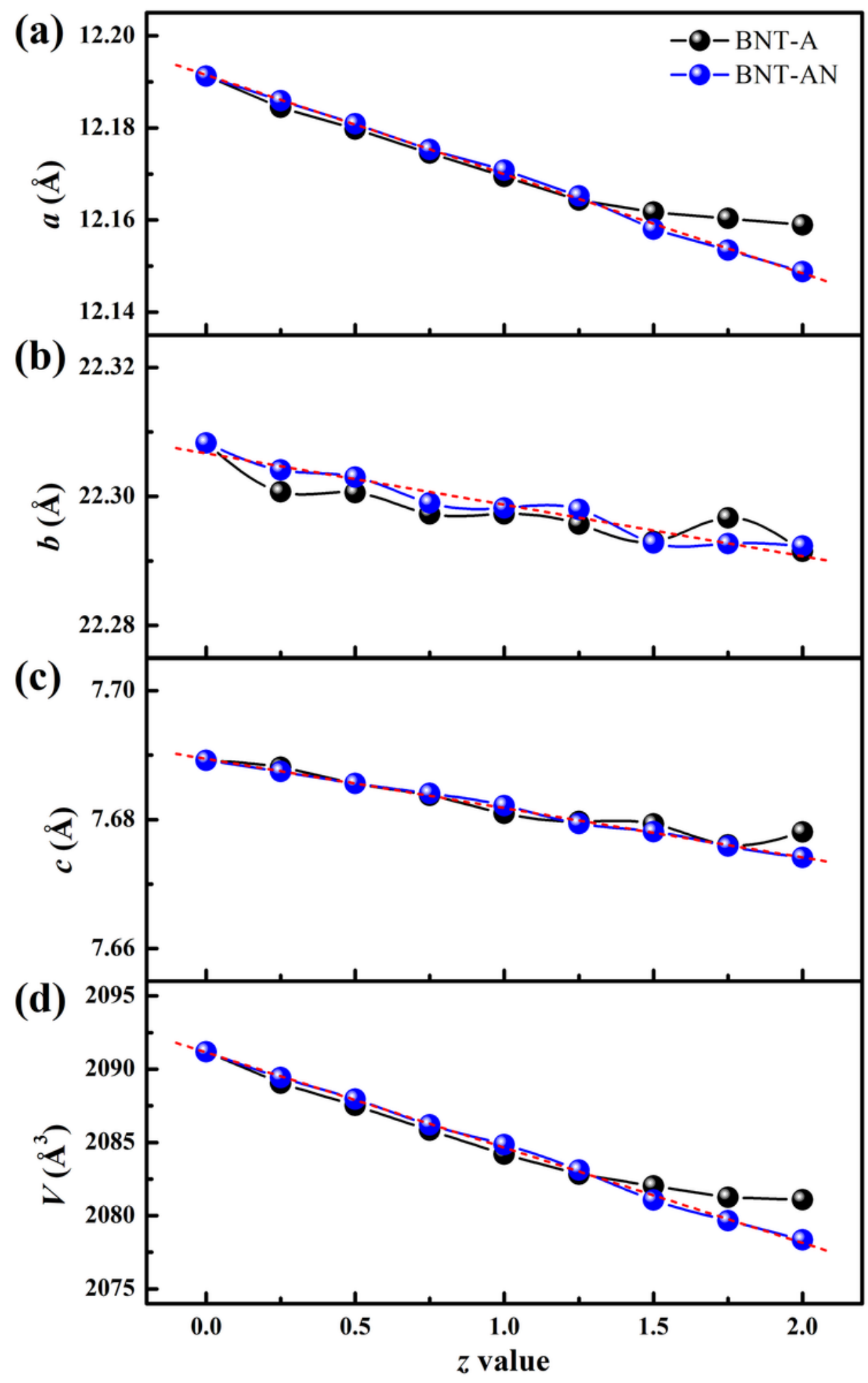

Figure 4

The lattice parameters (a) a, (b) b, (c) c, and (d) the cell volume of the BNT-A and BNT-AN $(0 \leq z \leq 2)$ ceramics. 


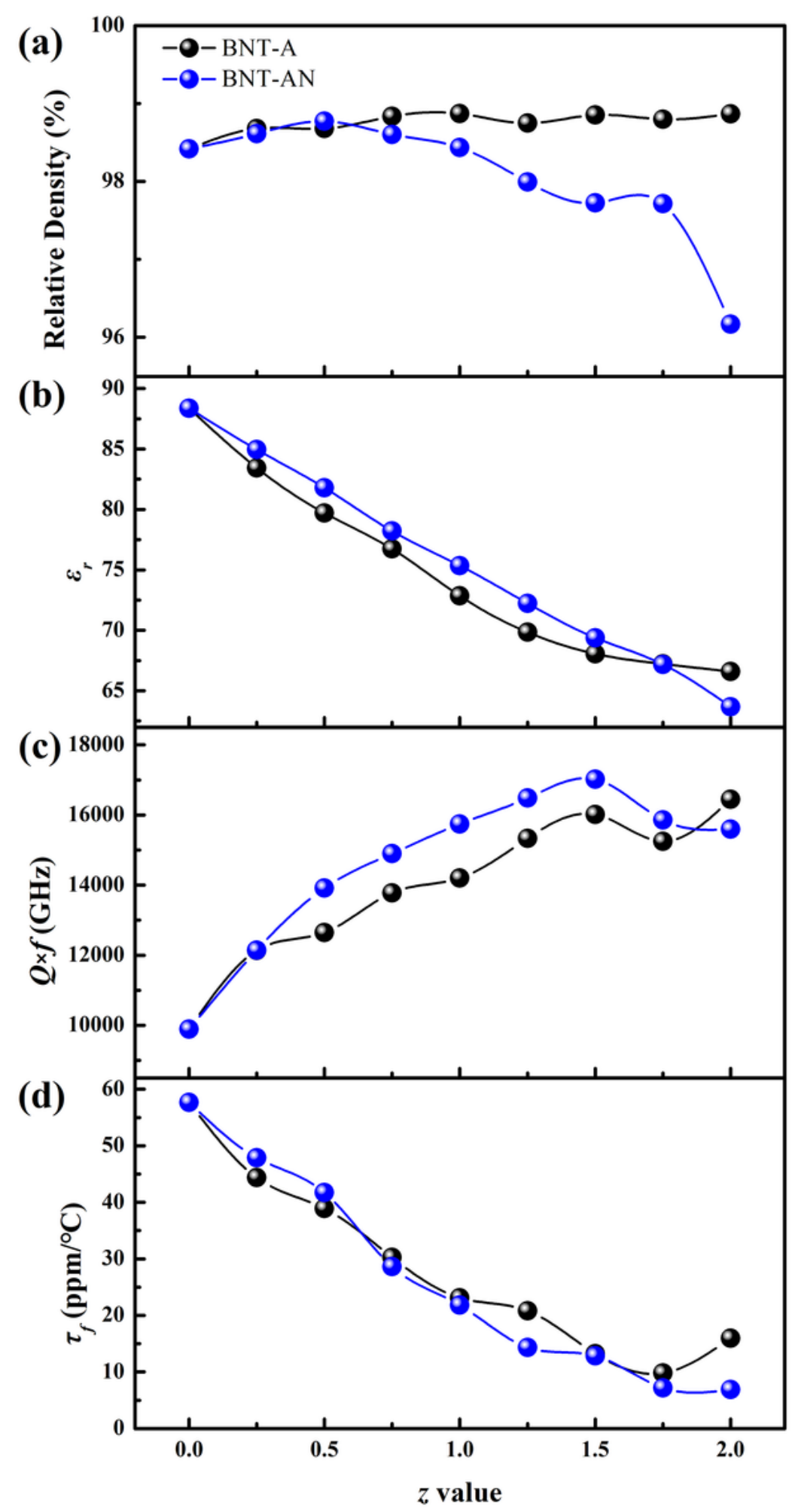

Figure 5

(a) Relative densities, (b) $\varepsilon r$ values, (c) Qxf values and (d) tf values of the BNT-A and BNT-AN $(0 \leq z \leq 2)$ ceramics. 


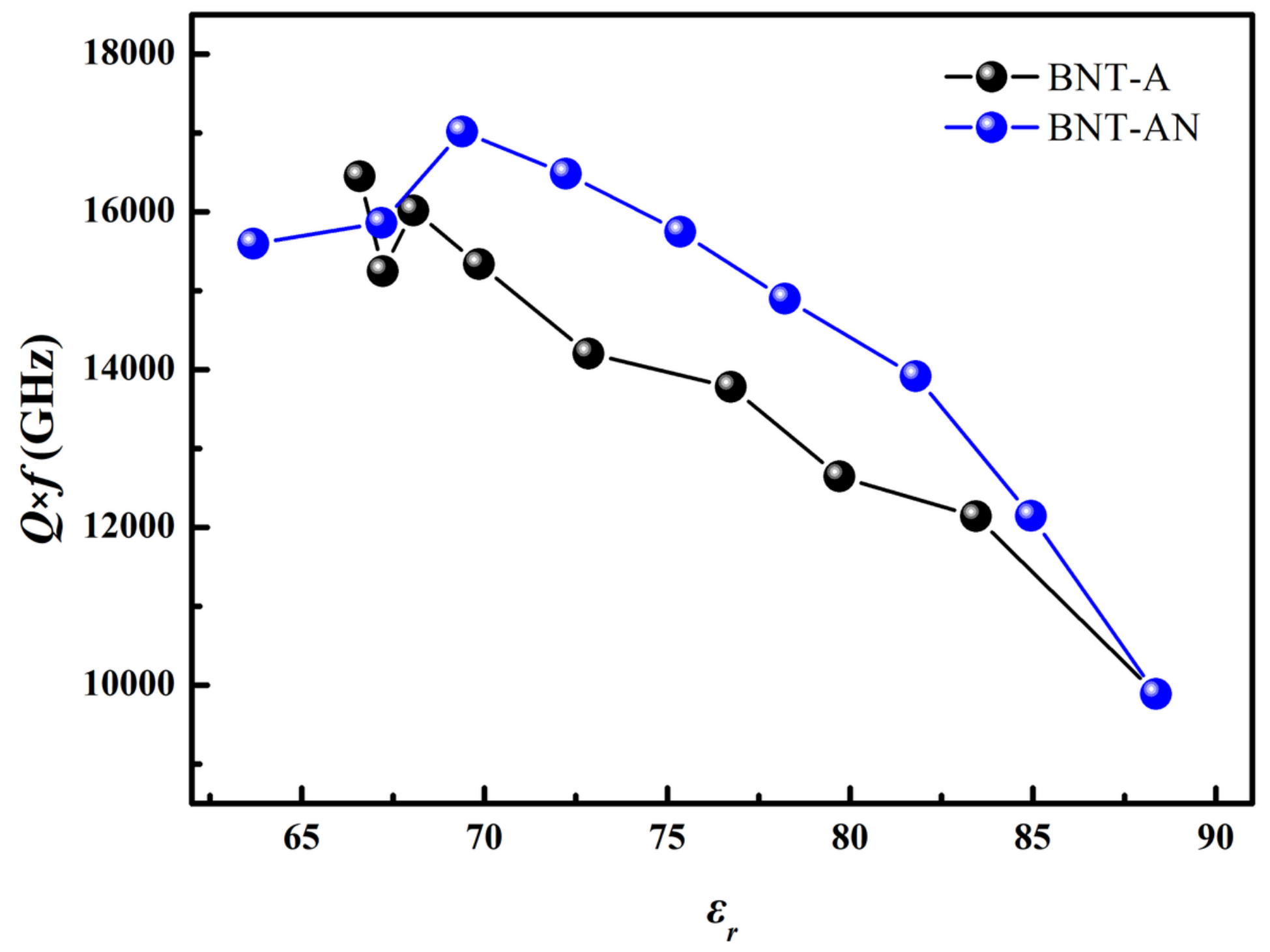

Figure 6

The $\varepsilon r$ and $Q \times f$ values of the BNT-A and BNT-AN $(0 \leq z \leq 2)$ ceramics. 


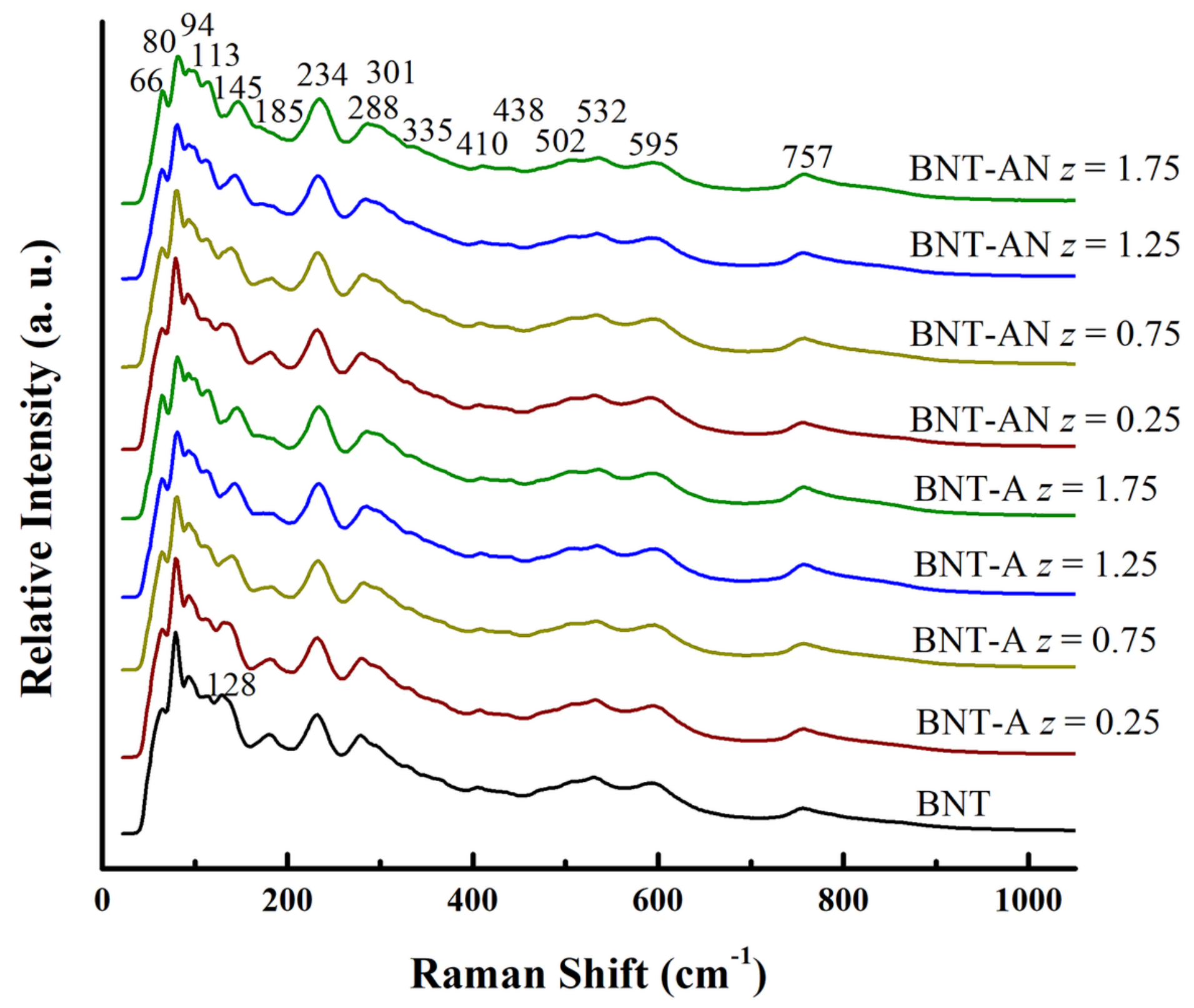

Figure 7

Raman spectra of the BNT-A and BNT-AN $(z=0,0.25,0.75,1.25,1.75)$ ceramics. 


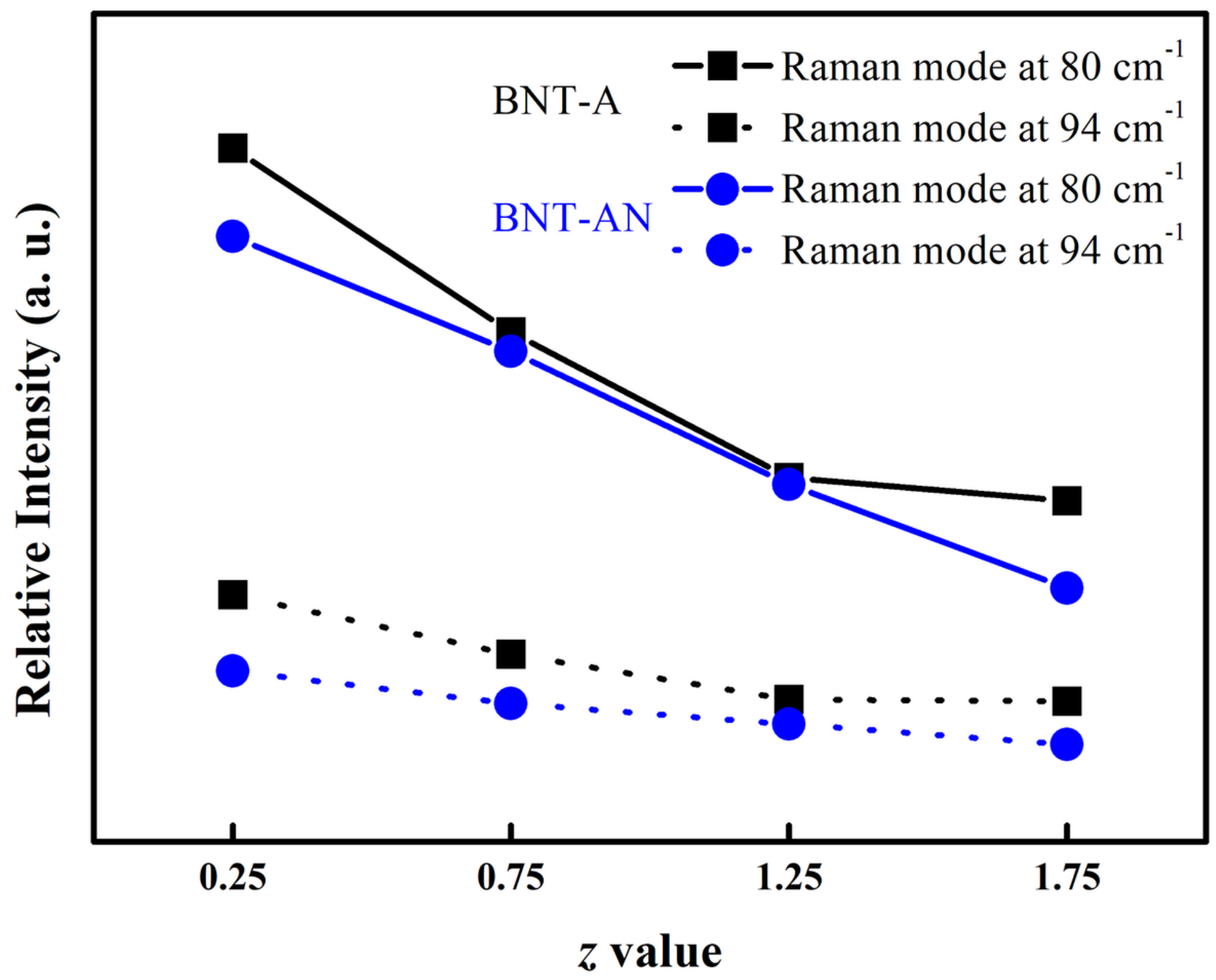

Figure 8

The relative intensities of Raman modes at $80 \mathrm{~cm}-1$ and $94 \mathrm{~cm}-1$ of the BNT-A and BNT-AN $(z=0.25,0.75$, $1.25,1.75)$ ceramics. 

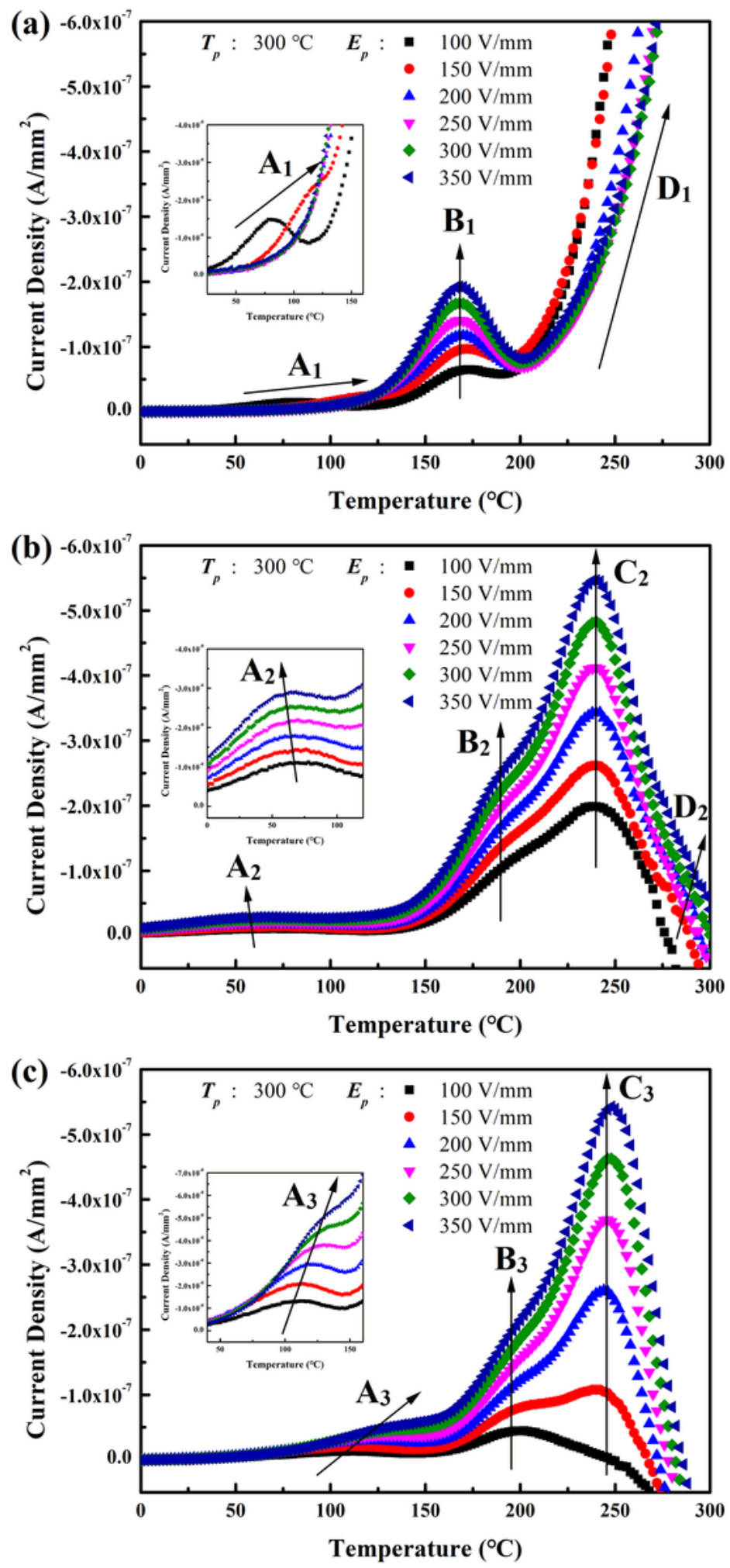

Figure 9

TSDC curves of (a) the BNT ceramics, $(b)$ the BNT-A ( $z=1.25)$ ceramics, and (c) the BNT-AN $(z=1.25)$ ceramics under $\mathrm{Tp}=300^{\circ} \mathrm{C}$ and $100 \mathrm{~V} / \mathrm{mm} \leq \mathrm{Ep} \leq 350 \mathrm{~V} / \mathrm{mm}$.

\section{Supplementary Files}


This is a list of supplementary files associated with this preprint. Click to download.

- Figs1.tif

- SupplementMaterial.docx

- Tables1.docx

- Tables2.docx 